\title{
Implementation of arduino pro mini and ESP32 cam for temperature monitoring on automatic thermogun IoT-based
}

\author{
P. W. Rusimamto ${ }^{1}$, Endryansyah ${ }^{2}$, L. Anifah ${ }^{3}$, R. Harimurti ${ }^{4}$, Y. Anistyasari ${ }^{5}$ \\ 1,2,3 Department of Electrical Engineering, State University of Surabaya, Surabaya, Indonesia \\ ${ }^{4,5}$ Department of Informatic Engineering, State University of Surabaya, Surabaya, Indonesia
}

\begin{abstract}
Article Info
Article history:

Received Dec 22, 2020

Revised Jul 12, 2021

Accepted Jul 18, 2021

Keywords:

Arduino pro mini

Automatic thermogun

ESP32 cam

IoT

Temperature monitoring

ABSTRACT

The purpose of this research is to monitor the temperature by applying arduino pro mini and ESP32 cam using IoT technology which is connected to a web interface. Arduino is used as the main brain of the system where arduino will read data from the MLX90614-ACF temperature sensor. Sensor data will continue to be sent to the server by arduino via the ESP32 cam module. This tool can also take pictures and send images automatically at the same time when measuring temperature. The captured image will automatically be sent to the PC/laptop monitor screen via the website. The website is used to display and monitor the results of temperature measurement data and display the image results from the ESP32 cam. The process of taking photos and measuring body temperature is done automatically. Users can also view data from sensors and photo data sent by arduino and ESP32 cam via the provided web interface. From the test results, this system has been running well where all sensor data is sent and can be displayed on the website. Images and measurement data results are sent to the monitor screen via the website interface with a measurement accuracy of $99.6 \%$.
\end{abstract}

This is an open access article under the CC BY-SA license.

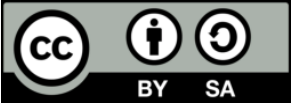

Corresponding Author:

Puput Wanarti Rusimamto

Department of Electrical Engineering

State University of Surabaya

Kampus Ketintang, Surabaya, Indonesia

Email: puputwanarti@unesa.ac.id

\section{INTRODUCTION}

The internet of things (IoT) is an interesting study material in the current era. IoT is currently growing and widely used where every electronic device around us can be connected to each other so that complex communications can be formed. With this IoT technology we can connect objects such as lights, fans, smartphones, sensors and actuators to the internet so that we can control them and allow for forms of communication between objects and humans [1]. So that with Iot human will be easier to monitor and check all activities remotely. IoT, if described more specifically, has been controling and monitoring the technology. Control technology connected to IoT can be developed to support the current government's target of building making Indonesia 4.0. Utilization of IoT can be applied to devices for automatic thermogun by utilizing arduino and ESP32 cam [2]. The results of Lilik's research [3] which made a monitoring system for the patient's body temperature and heart rate using IoT, was able to develop e-health technology and assist medical personnel in monitoring the patient's condition. IoT in the health sector is also used as a monitoring technology for fall risk assessment, fall prevention and fall detection in healthy elderly using 2 sensors, namely accelerometer and gyroscope [4].

Other researchers have developed IoT and Arduino applications, including Murad et al. [5] have succeeded in developing smart home systems with two levels of security based on IoT technology. They have 
used Arduino and NodeMCU microcontrollers. Velasco et al. [6] have applied the arduino yun and arduino uno to monitor the stock in the refrigerator wirelessly by accessing the android application. Rahman et al. [7] have successfully developed a temperature and humidity monitoring system using the Arduino Mega 2560 R3. Rafiq et al. [8] have applied infrared sensor and arduino to improve electricity efficiency based on IoT. Meanwhile, the implementation of the embedded real-time temperature and moisture monitoring system using the IoT-based Arduino application has been carried out by Hashim et al. [9].

Corona virus or known as Covid-19 has been epidemic in the country since the end of February 2020. With this case the government has implemented several policies, including urging people not to leave the house to break the chain of spreading the virus. If you leave the house, you must wear a mask, keep your distance and clean your hands. As has been informed through various media, that the corona virus can be transmitted through physical contact with symptoms that are very similar and familiar to illnesses to Indonesian and the world.

Early prevention of the spread of Covid-19 is carried out by checking body temperature. This has been done by the government at several entrances to public places and shopping, because it is a location that has the potential to transmit Covid-19. Body temperature checks is carried out by officers generally use a thermogun. The use of the thermogun by officers is still felt to be ineffective, because officers have to approach the object to be measured in temperature. This condition raises the need for automatic thermogun. Automatic thermogun can help officers, where the measurement of body temperature without having to be done by the officer because the tool takes measurements of body temperature automatically. A related research to this research is the design of a digital contactless infrared thermometer based on Arduino nano [10]. All processes in this study have gone well that the digital contactless infrared thermometer is able to measure human body temperature automatically.

Based on the description above, and oberserved the current situation that has occurred in the Covid19 pandemic, researchers made a device to detect a person's body temperature that is easy to apply to government agencies or public places. The device is made using Arduino Pro mini and ESP32 Cam and sent the results of measurements of body temperature and condition of a person via a web interface that has been made previously [11]. The advantage of this research is that there is a photo-taking feature that is sent via a web interface to find out whether a person is healthy or sick after measuring the temperature.

\section{RESEARCH METHOD}

The research method used is engineering research. This study applies science into a design in order to obtain performance in accordance with specified requirements [12]. The design is a synthesis of design elements combined with the scientific method into a model that meets certain specifications. Research starts from determining design specifications that meet the specified specifications, selecting the best alternative, and proving that the selected design can meet the specified requirements in an efficient, effective and low cost. Computer software research can be classified as engineering research [13].

The research steps carried out are as follows:

a) Literature study: at this stage, data collection and theoretical assessment are carried out regarding the materials needed for the required design. The materials collected and reviewed are either literature needed for both software and hardware

b) Design: at this stage the design is carried out both in software and hardware design. The results at this stage are hardware designs obtained both block diagrams and circuits based on the electronic components that have been obtained and the software design and software flow are obtained

c) Simulation:at this stage, a simulation is carried out on the software and hardware design based on the design results in the previous stage in order to obtain simulation data on the function of each part of the software and hardware

d) Implementation: at this stage, a combination of hardware and software is carried out. The result is synchronization between software and hardware that has been designed and simulated.

e) Verification: at this stage, the verification process is carried out on the tools that have been made with the simulation results of software and hardware. The result at this stage is that the tool can measure temperature automatically, find out human health conditions, take photos, and be able to send measurement data and photo images to the web interface page.

f) Testing: at this stage, a final test is carried out on the system that has been created to determine the level of success, whether it is in accordance with the scenario of the objectives to be achieved.

\subsection{Proximity sensor}

The design of an automatic temperature measuring device in this study uses a proximity sensor and a DC motor drive. The proximity sensor used is an infrared sensor Type E18-D80NK as shown in Figure 1. 
This infrared sensor can be powered with $5 \mathrm{~V}$ and detection distance can be adjusted from $3 \mathrm{~cm}$ to $80 \mathrm{~cm}$ with NPN output. It can be used at automation machine and mobile robot for obstacle detecting. The sensor provides a non-contact detection. The implementations of modulated IR signal immune the sensor to the interferences which caused by the normal light of a light bulb or the sun light [14].

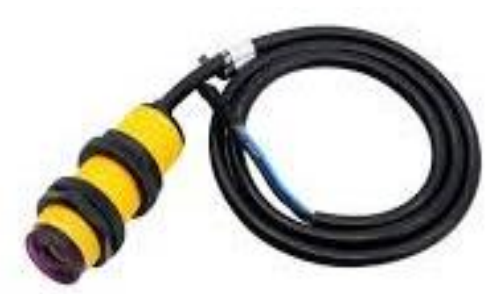

Figure 1. Infrared sensor Type E18-D80NK

\subsection{Microcontroller}

A microcontroller is a single chip computer that includes a minimum of a microprocessor, memory, and input-output modules. Depending on the complexity, some microcontrollers include additional components such as counters, timers, interrupt control circuits, serial communication modules, analog-todigital converters, digital signal processing modules, and so on [15]. Microcontrollers are used in products and tools that are automatically controlled, such as machine control systems, remote controls, office machines, household appliances, heavy equipment, and toys. The presence of a microcontroller makes electrical control for various processes more economical. With the use of this microcontroller: i) the electronic system will be more compact, ii) the electronic system design will be faster because most of the system is software that is easily modified, and iii) the search for interference is easier to trace because the system is compact.

\subsection{Arduino pro mini}

Arduino pro mini is a microcontroller board with ATmega328. Several studies [16], [17] used Arduino pro mini to control the tools. The Arduino pro mini has 14 digital input/output pins, of which 6 can be used as PWM outputs, 6 analog inputs, an on-board resonator, a reset button, and holes for pin header mounting. The six-pin header can be connected to any FTDI or sparkfun board breakout cable to provide USB power and communication for the board. The Arduino Pro Mini is meant for semi-permanent installation on an object. The pro mini allows the use of various types of connectors or direct soldering of cables. All important data sent wirelessly by arduino pro mini can be displayed in real time. Layout pins are compatible with Arduino Mini [18]. Arduino pro mini is shown in Figure 2.

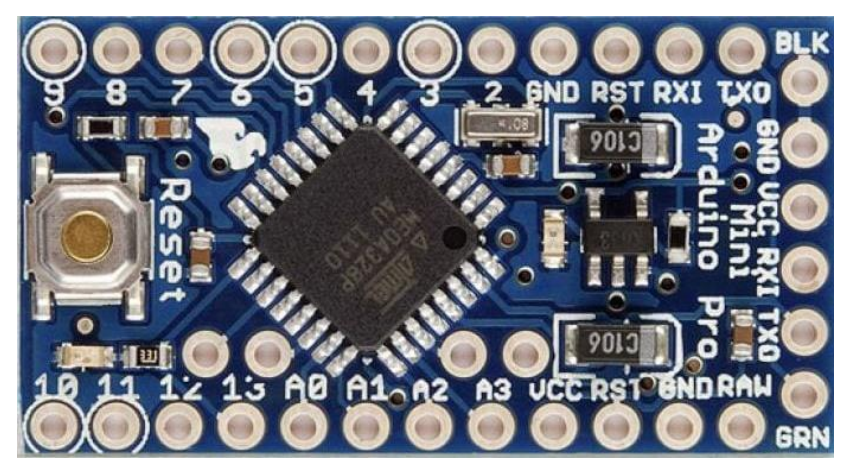

Figure 2. Arduino pro mini [18]

The Arduino Pro Mini can be powered with an FTDI cable or breakout board connected to its sixpin header, or with a $3.3 \mathrm{~V}$ or $5 \mathrm{~V}$ voltage (depending on the model) on the VCC pin. There is a voltage regulator on the board so it can accept voltages up to $12 \mathrm{VDC}$. If your power supply is regulated to the board, make sure it is connected to the "RAW" pin on not VCC. 


\subsection{ESP32 cam}

This module is a Wi-Fi module that is equipped with a camera. From this module it can be used for various purposes, for example for CCTV, taking pictures and so on. Another feature is that it can detect faces and face recognition. The ESP32 cam has a very competitive small size camera module that can operate independently with a minimum system. ESP32 cam can be used widely in various IoT applications. It is suitable for smart home devices, industrial wireless control, wireless monitoring, QR wireless identification, wireless positioning system signals and other IoT applications. Several studies [19], [20] have used ESP32 cam as an ideal solution for IoT applications.

\subsection{MLX90614 infrared temperature sensor}

The MLX90614 sensor is an infrared thermometer that is used to measure temperature without coming into contact with an object [21]. This sensor consists of an infrared based temperature sensitive detector chip and an ASSP signal conditioner which is integrated with the TO-39. This sensor is supported by a low noise amplifier, 17 bit ADC, DSP unit and thermometer which has high accuracy and resolution. The thermometer is calibrated with a digital output from the PWM and SMBus. As a standard 10-bit PWM will show a temperature change that is measured continuously with a temperature range on the sensor minus 40 to 120 degrees celsius and an object temperature range from -70 to 380 degrees celsius with an output resolution of 0.14 degrees celsius. The circuit and physical display of the MLX90614 temperature sensor can be seen in Figure 3.

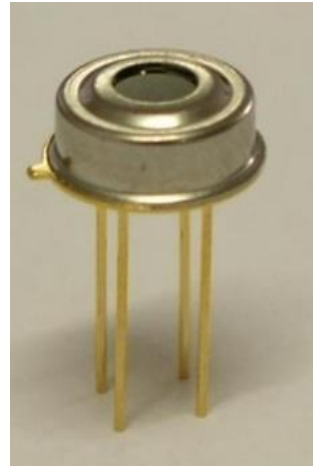

(a)

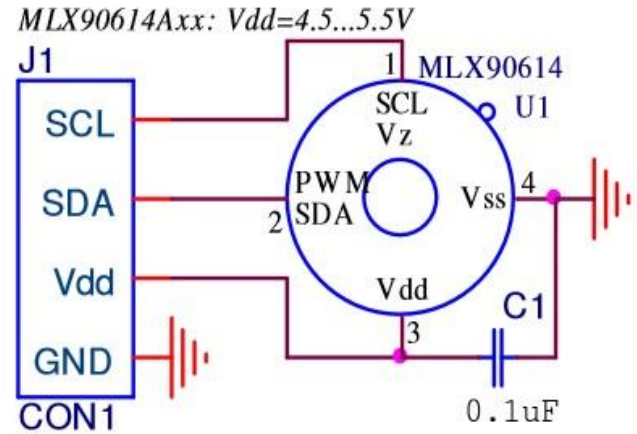

(b)

Figure 3. MLX90614 infrared temperature sensor. (a) physical display, (b) electronic circuit [22]

The PWM pin can be used as a temperature change relay (to as input), which is easy and cheap to use in a thermostat or temperature warning (freeze or boil). Temperature thresholds are easy to program. On the SMBus, this feature has a function as an interrupt on the processor that can trigger a reading of all the slaves on the bus and determine the actual conditions. Normally, the MLX90614 sensor can sense objects with an emissivity of 1 . However this sensor can be calibrated easily to sense objects with an emissivity of 0.1 to 1 . MLX90614 can use 2 alternative voltage sources, namely $5 \mathrm{~V}$ or $3 \mathrm{~V}$ batteries. The pin position can be seen in Figure 4 and the description is in Table 1.

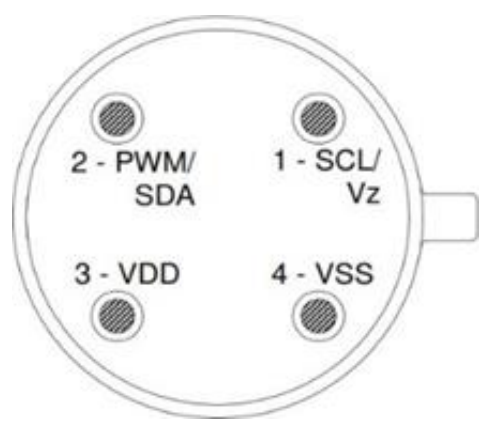

Figure 4. MLX90614 sensor pin description [23], [24] 
Table 1. Description of MLX90614 sensor pin name and function [24]

\begin{tabular}{cc}
\hline Pin Name & Function \\
\hline VSS & Ground \\
SCL/Vz & Input Clock Serial for Wired Communication Protocol 2 \\
PWM/SDA & Digital Input/Output \\
VDD & External Voltage Source \\
\hline
\end{tabular}

\subsection{Buzzer}

Buzzer is an electronic component which has function to convert electric vibrations into sound vibrations [25]. The buzzer as shown in Figure 5. Buzzer is usually used as an indicator that a process has been completed or an error has occurred in a device [26].

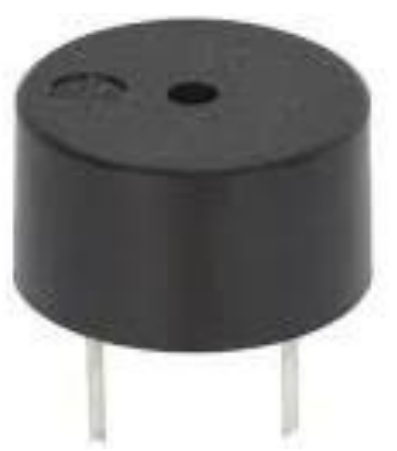

Figure 5. Buzzer [26]

\section{RESULTS AND DISCUSSION}

The design of this tool is divided into two main parts the first is hardware design and the second is software design. Design software includes flowcharts and web interface design. Figure 6 shows a block diagram regarding hardware design.

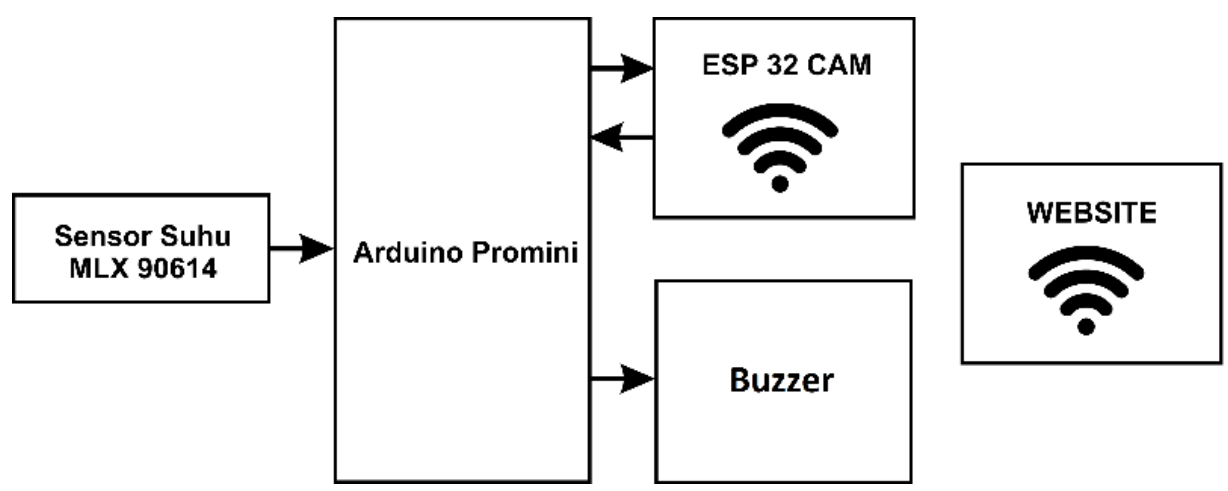

Figure 6. Block diagram of automatic thermogun implementation with arduino promini and ESP32 cam

Figure 6 shows the block for tools or hardware and the block for the website. Tool blocks include the arduino promini, ESP32 cam, MLX 90614 temperature sensor, and buzzer. This block can send and receive data to and from the server. Arduino is used as the main brain of the system where arduino will read data from the temperature sensor. The sensor data will continue to besent to the server by Arduino via the ESP32 cam module. The ESP32 cam module can also send photos automatically when motion is detected [20]. The arduino will command the ESP32 Cam to take a picture and send it to the server. This is one of the real requirement of the arduino in the system [27]. Furthermore, the hardware assembly as shown in Figure 7. The software design is made by a flowchart for the system shown in Figure 8. 


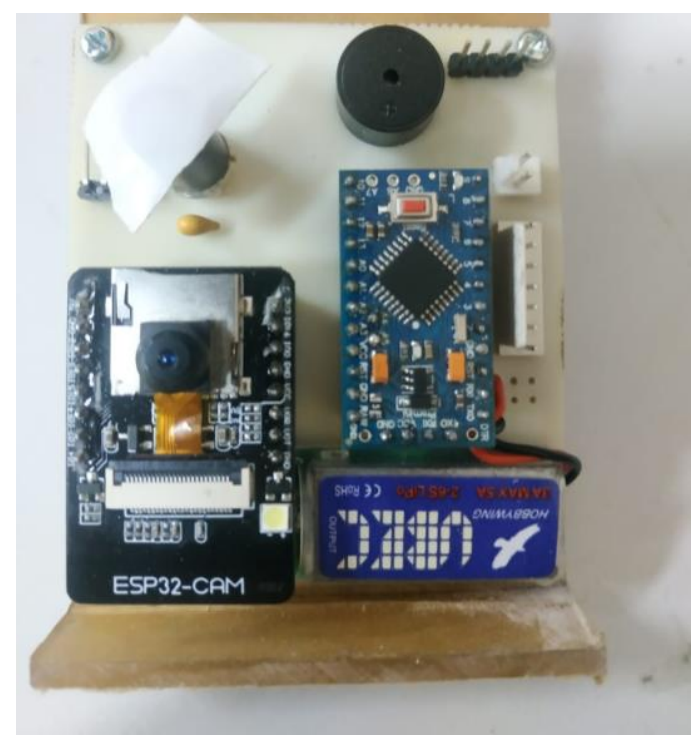

Figure 7. Hardware design result

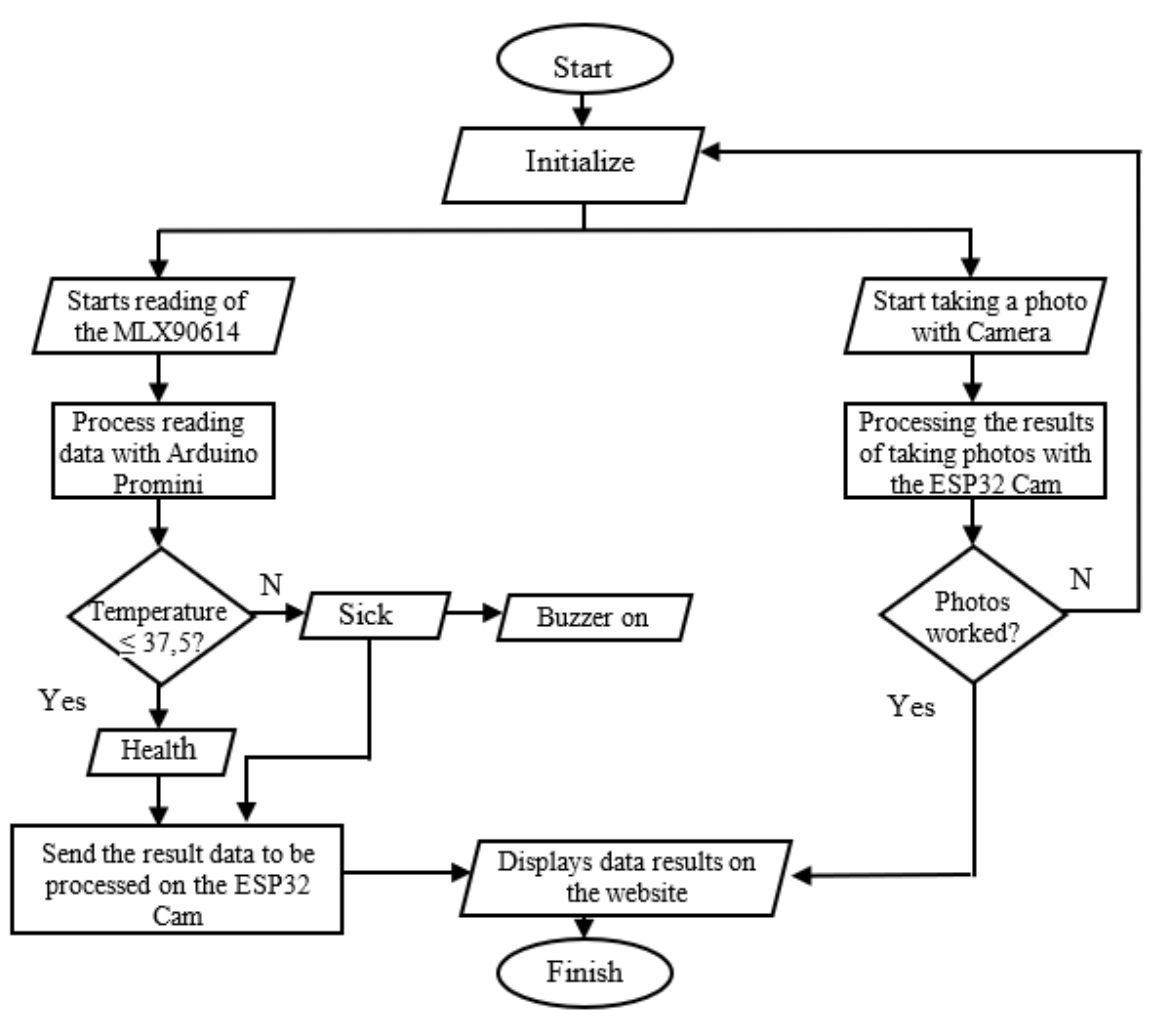

Figure 8. Flowchart of the whole system

There are two types of data transfer, that are serial data transfer from arduino and client-server data transfer on ESP32 cam. For the serial data speed, settings are made in the arduino programming that is using the baud rate value on the Arduino, the greater the baud rate value, the higher the transfer speed. However, because communication that involves electrical signals and data synchronization processes is very susceptible to errors and noise, it is recommended not to exceed the speed of 115,200 bps for communication on the arduino [28]. Meanwhile, the speed of the client-server data depends on the speed of the internet signal used, how much data is sent from the server to the client and it can also go through the delay value set during programming. 
In terms of sending data, the arduino pro mini will read data from the MLX90614 temperature sensor regarding human body temperature. The reading data will be sent serially via the ESP32 cam so that it can be displayed on the website interface page. If the temperature is greater than $37.5 \mathrm{o} \mathrm{C}$, the Arduino will activate the buzzer to indicate that the body whether is healthy or sick. Then the data received by the ESP32 cam will be sent to a server with a WiFi connection. When the MLX90614 temperature sensor has finished processing the body temperature reading, Arduino will immediately send a command to the ESP32 cam to take a picture and send it to the website interface page [11].

The next part is web interface design. In this design, there are 3 parts that display information about human body temperature, human body condition and photo images that have been captured automatically. After all the designs and programs have been created that involve the process of verifying the function of each part, the next step is testing the tools. The tests carried out include testing data delivery to the website, and testing automatic image capture. In the data delivery test section, testing is carried out related to the sending of sensor data which includes data from the MLX90614 temperature sensor as well as sending the capture results from the ESP32 cam. This test is intended to see whether the data is successfully displayed or not on the sensor result data page. To find out the average temperature measurement error on the MLX90614, a comparison was made by measuring temperature using a thermogun.

Table 2 shows the results of testing the MLX90614 temperature sensor data where from the test results all sensor data read from the Arduino Pro Mini and sent via ESP32 Cam was successfully sent to the server and successfully displayed on the website interface page. While the measurement results from MLX90614, as shown in Figure 9. With an accuracy of measurement of 99.6\% [29]. The average temperature measurement error on the MLX90614 with a thermogun is $3.8 \%$.

Table 2. Data transmission of MLX90614 temperature sensor results and photo capture results

\begin{tabular}{ccccccccccc}
\hline \multirow{2}{*}{ Componen Name } & 1 & 2 & 3 & 4 & 5 & 6 & 7 & 8 & 9 & 10 \\
\hline Thermogun & 36.3 & 35.61 & 35.23 & 35.15 & 35.26 & 35.35 & 35.15 & 35.2 & 35.55 & 35.2 \\
MLX90614 & 36.5 & 35.63 & 35.22 & 35.17 & 35.25 & 35.37 & 35.17 & 35.23 & 35.53 & 35.31 \\
Camera & Ok & Ok & Ok & Ok & Ok & Ok & Ok & Ok & Ok & Ok \\
Buzzer & Off & Off & Off & Off & Off & Off & Off & Off & Off & Off \\
\hline
\end{tabular}

\section{MLX90614}

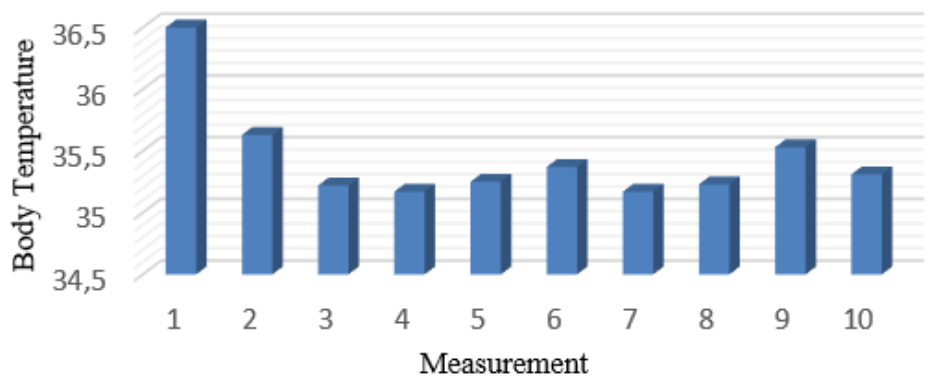

Figure 9. MLX90614 measurement chart

The result data that has been processed and sent via the ESP32 cam can be seen by the user on the website interface page. Figure 10 shows the MLX90614 temperature sensor data and the camera capture results displayed on a web page where the page contains data related to temperature data, a person's condition, and the results of the capture from the camera. While the results of the tool design are shown in Figure 11. In general, the test results have been successful, but there are obstacles when the tool is placed outside the room. In the process of object initialization, we often get interference with the objects around it, because the proximity sensor is too sensitive and sometimes the proximity sensor cannot detect the human body at a predetermined distance. The next research proposal is to change the mechanical construction so that it will limit the sensitivity of the proximity sensor which always detects objects around it. Furthermore, the microcontroller can use the arduino mega or arduino uno so that the reading speed is more stable. 


\section{9 쟆 ICC (UNESA CRISIS CENTRE)}

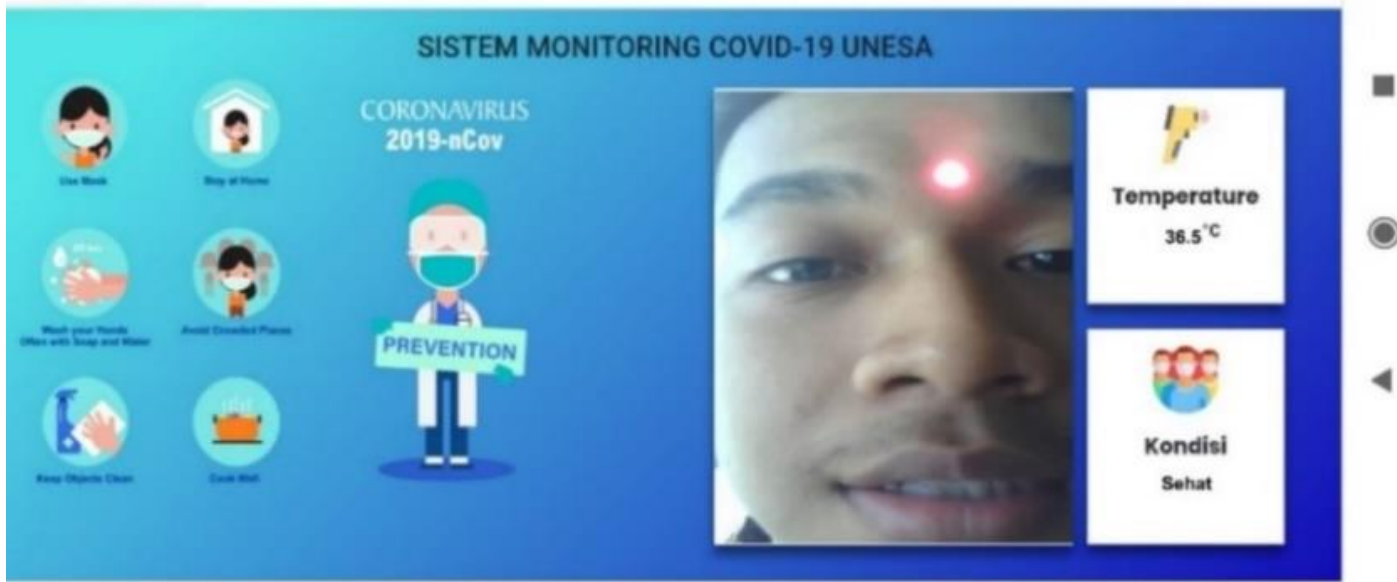

Figure 10. Website interface page

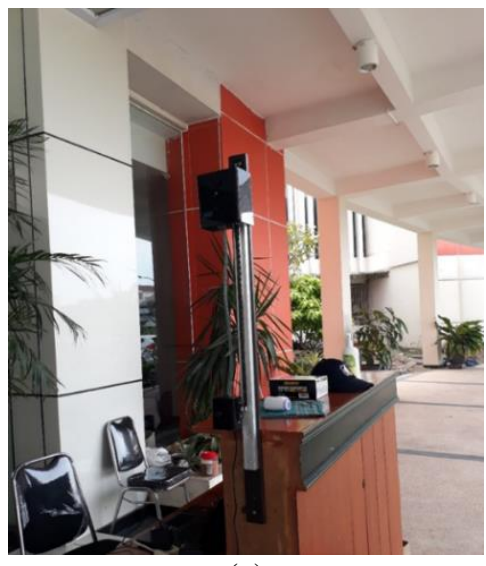

(a)

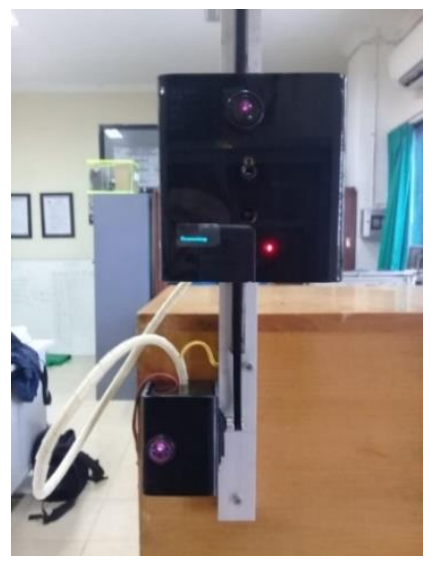

(b)

Figure 11. (a) results of automatic thermogun design in unesa campus rectorate building [11], (b) results of automatic thermogun design in unesa control system laboratory

\section{CONCLUSION}

The implementation of temperature monitoring with arduino promini and ESP32 cam for this automatic thermogun has been successfully made and ran well. The test results of all sensor data read from arduino pro mini and sent via ESP32 cam were successfully sent to the server and successfully displayed on the website interface page. The measurement accuracy of the MLX90614 is $99.6 \%$. However, there are problems with the proximity sensor, which is too sensitive, making it easy to detect objects in the vicinity. This can be overcome by designing the mechanical construction in such a way that it can limit the sensitivity of the proximity sensor. It can be used in the next proposal to help measure body temperature as an early detection of Covid-19 symptoms, which can be placed at the entrance of a building or room.

\section{ACKNOWLEDGEMENTS}

The author would like to thank profusely to Surabaya State University, especially the Department of Electrical Engineering, which has provided the opportunity for the author to do this research and allow the author to complete it without any difficulty. 


\section{REFERENCES}

[1] R. Atiqur and Y. Li, "Automated smart car parking system using raspberry Pi 4 and iOS application," International Journal of Reconfigurable and Embedded Systems, vol. 9, no. 3, pp. 229-234, Nov. 2020, doi: 10.11591/ijres.v9.i3.pp229-234.

[2] V. Raj, A. Chandran BS and A. Prabha RS, "IoT Based Smart Home Using Multiple Language Voice Commands," 2019 2nd International Conference on Intelligent Computing, Instrumentation and Control Technologies (ICICICT), pp. 1595-1599, 2019, doi: 10.1109/ICICICT46008.2019.8993202.

[3] L. Anifah, P. W. Rusimamto, S. I. Haryudo, Nurhayati, Warju, and Haryanto, "Internet of Things-Based Monitoring System of Patients Using W1209 Digital Thermostat and Pulse Sensor," The International Joint Conference on Science and Engineering (IJCSE 2020), vol. 196, pp. 287-291, Nov. 2020, doi: 10.2991/aer.k.201124.052.

[4] R. Rucco et al., "Type and Location of Wearable Sensors for Monitoring Falls during Static and Dynamic Tasks in Healthy Elderly: A Review," Sensors, vol. 18, no. 1613, pp. 1-20, 2018, doi:10.3390/s18051613.

[5] M. Murad, O. Bayat, and H. M. Marhoon, "Design and implementation of a smart home system with two levels of security based on IoT technology," Indonesian Journal of Electrical Engineering and Computer Science, vol. 21, no. 1, pp. 546-557, Jan. 2021, doi: 10.11591/ijeecs.v21.i1.

[6] J. Velasco et al., "Internet of things-based (IoT) inventory monitoring refrigerator using arduino sensor network," Indonesian Journal of Electrical Engineering and Computer Science, vol. 18, no. 1, pp. 508-515, Apr. 2020, doi: 10.11591/ijeecs.v18.i1.

[7] R. A. Rahman, U. Raba, and S. Ahmad, "IoT based temperature and humidity monitoring framework," Bulletin of Electrical Engineeringand Informatics, vol. 9, no. 1, pp. 9-11, Feb. 2020, doi: 10.11591/eei.v9i1.1557.

[8] A. A. Rafiq, S. D. Riyanto, and R. Wardani, "An improved electricity efficiency method based on microcontroller and IoT with infrared sensor," TELKOMNIKA, (Telecommunication, Computing, Electronic, and Control), vol. 18, no. 2, pp. 985-993, Apr. 2020, doi: 10.12928/telkomnika.v18i2.14889.

[9] F. Hashim, R. Mohamad, M. Kassim, and S. I. Suliman, "Implementation of embedded real-time monitoring temperature and humidity system," Indonesian Journal of Electrical Engineering and Computer Science, vol. 16, no. 1, pp. 184-190, Oct. 2019, doi: 10.11591/ijeecs.v16.i1.pp184-190.

[10] M. A. Al Mamun, M. A. Hossain, M. M. Rahman, M. I. Abdullah, and M. S. Hossain, "Design and Development of Arduino Based Contactless Thermometer," IITM Journal of Management and IT, vol. 11, no. 1, pp. 59-62, June 2020, Online ISSN: 2349-9826.

[11] P. W. Rusimamto, R. Harimurti, Y. Anistyasari, Endryansyah, and L. Anifah, "Design and Implementation of Thermal Body System Employing Thermal Sensor MLX 90614 for Covid-19 Symptoms Early Detector," Advances in Engineering Research, International Joint Conference on Science and Engineering (IJCSE 2020), vol. 196, pp. 317-321, Nov. 2020, doi: 10.2991/aer.k.201124.058.

[12] J. Tolvanen, M. Rossi, and H. Liu, "Method Engineering: Current research directions and implications for future research," Method Engineering, pp. 296-317, 1996, doi: 10.1007/978-0-387-35080-6.

[13] K.. Nallaperumal, "Engineering Research Methodology A Computer Science and Engineering and Information and Communication Technologies Perspective," PHI Learning Private Limited, Dec. 2013.

[14] X. Xu et al., "Design of Semi-Automatic Banana Bud Removal Machine," IFAC-PapersOnLine, vol. 51, no. 17, pp. 146-151, 2018, doi: 10.1016/j.ifacol.2018.08.078.

[15] A. Stacul et al., "A hardware system with ARM-based data processing for nano satellites," International Journal of Reconfigurable and Embedded Systems, vol. 9, no. 2, pp. 102-108, July 2020, doi: 10.11591/ijres.v9.i2.pp102-108.

[16] M. Taştan, "IoT Based Wearable Smart Health Monitoring System," Celal Bayar University Journal of Science, vol. 14, no. 3, pp. 343-350, Sep. 2018, doi: 10.18466/cbayarfbe.451076.

[17] S. Das, S. Patro, R. Das, and A. Mishra, "Arduino based Safety Device for the Visually Challenged," 2019 International Conference on Communication and Signal Processing (ICCSP), pp. 601-605, Apr. 2019, doi: 10.1109/ICCSP.2019.8697987.

[18] P. E. Aris, Arduino Pro Mini, 2019. [Online]. Available: https://www.arduinoindonesia.id/2019/01/arduino-promini.html. [accessed Nov 23, 2020].

[19] M. J. Junior, O. B. Maia, H. Oliveira, E. Souto, and R. Barreto, "Assistive Technology through Internet of Things and Edge Computing," IEEE 9th International Conference on Consumer Electronics (ICCE-Berlin), pp. 330332, Sep. 2019, doi: 10.1109/ICCE-Berlin47944.2019.8966148.

[20] M. Babiuch and J. Postulka, "Smart Home Monitoring System Using ESP32 Microcontrollers," Internet of Things, Nov. 2020, doi:10.5772/intechopen.94589.

[21] R. Kansara and J. Chauhan, "The Future of Smart Clothing: A Kit Designed to Detect Vital Health Parameters," 2018 Second International Conference on Intelligent Computing and Control Systems (ICICCS), pp. 535-539, 2019, doi: 10.1109/ICCONS.2018.8663027.

[22] K. Dimitrov, "DIY: a 5 Minutes Contactless OLED Thermometer With Arduino and MLX90614," [Online]. Available: https://www.instructables.com/DIY-a-5-Minutes-Contactless-OLED-Thermometer-With-/ (accessed Nov. 23, 2020)

[23] MLX90614 IR Thermometer Hookup Guide. Sparkfun.com. https://learn.sparkfun.com/tutorials/mlx90614-irthermometer-hookup-guide/all (accessed Nov 23, 2020).

[24] MLX90614 family Datasheet Single and Dual Zone, Melexis.com, Sep. 2019. [Online]. Available: https://www.melexis.com/en/documents/documentation/datasheets/datasheet-mlx90614 (accessed Nov. 23, 2020)

[25] M. P. Valente and I. B. De Paula, "Sensor based on piezo buzzers for simultaneous measurement of fluid viscosity and density," Measurement, vol. 152, 2020, doi: 10.1016/j.measurement.2019.107308.

[26] Arduino-Morse-Code-with-LED-and-Buzzer. GitHub.com. https://github.com/two-engineers2/Arduino-MorseCode-with-LED-and-Buzzer (accessed Nov. 23, 2020). 
[27] M. W. Hariyanto, A. H. Hendrawan, and Ritzkal, "Monitoring the Environmental Temperature Using Arduino and Telegram," Journal of Robotics and Control, vol. 1, no. 3, pp. 96-101, May 2020, doi: 10.18196/jrc.1321.

[28] M. Novák, J. Kalová and J. Pech, "Use of the Arduino Platform in Teaching Programming," 2018 IV International Conference on Information Technologies in Engineering Education (Inforino), pp. 1-4, 2018, doi: 10.1109/INFORINO.2018.8581788.

[29] M. C. Ortiz, L. A. Sarabia, M. S. Sanchez, and A. Herrero, "Quality of Analytical Measurements: Statistical Methods for Internal Validation," Comprehensive Chemometrics 2nd Ed.: Chemical and Biochemical Data Analysis, Elsevier, pp. 1-51, 2019, doi: 10.1016/B978-0-12-409547-2.14746-8.

\section{BIOGRAPHIES OF AUTHORS}
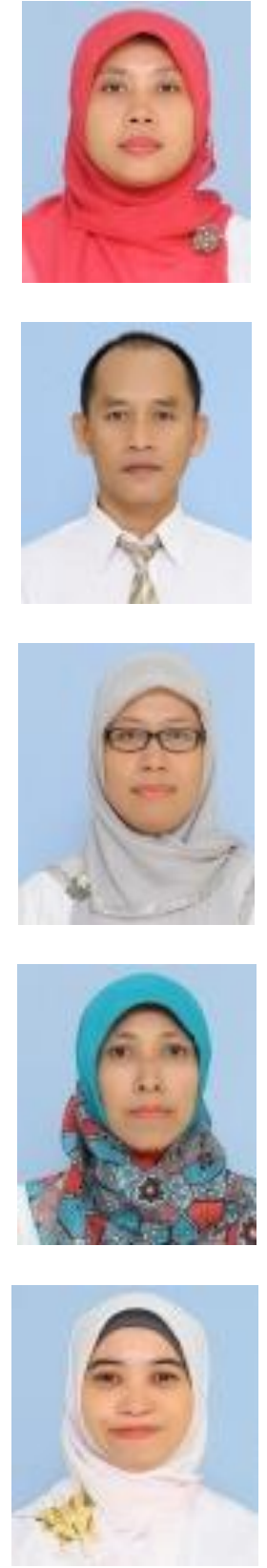

Puput Wanarti Rusimamto interest in control system engineering, vocational education. Graduated from the master program in Electrical Engineering Institut Teknologi Sepuluh Nopember Surabaya in the field of Control System Engineering with a thesis entitled Denoising Fetal Heart Rate Signals Using Wavelet Transformation. Currently studying at the doctoral program in vocational education in State University of Surabaya

Endryansyah interest in control system engineeering. Graduated from the master program in Electrical Engineering Institut Teknologi Sepuluh Nopember Surabaya in the field of Control System Engineering with a thesis entitled induction motor speed control system with fuzzy stator current estimation.

Lilik Anifah interest in artificial intelegence, image processing, electrical engineering, informatics. Graduated from the doctoral program in Electrical Engineering Institut Teknologi Sepuluh Nopember Surabaya in the field of image processing, with the title of the dissertation is determination of osteoarthritis severity on $\mathrm{x}$-ray images using kohonen self organizing map.

Rina Harimurti interest in computer science, vocational education. graduated from the master program in Electrical Engineering in the field of Computer Informatics Systems Gajah Mada University Yogyakarta with a thesis entitled semantic parsing for mailing addresses. Currently studying at the doctoral program in vocational education in State University of Surabaya.

Yeni Anistyasari interest in vocational education, computer science, multimedia processing, software engineering. Graduated from the master program in Electrical Engineering Institut Teknologi Sepuluh Nopember Surabaya in the field of informatics engineering with a thesis entitled weighted ontology for searching subject names based on document contents in the learning content management system. Currently studying at the doctoral program in vocational education in State University of Surabaya. 